\title{
Resolution and Racemization of a Planar-Chiral A1/A2-Disubstituted Pillar[5]arene
}

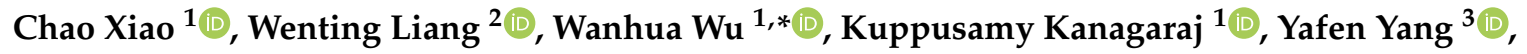 \\ Ke Wen ${ }^{3, *}$ and Cheng Yang ${ }^{1, *(D)}$ \\ 1 College of Chemistry and Healthy Food Evaluation Research Center, Sichuan University, Chengdu 610064, \\ China; xc6266@foxmail.com (C.X.); kanagaraj195@gmail.com (K.K.) \\ 2 Institute of Environmental Sciences, Department of Chemistry, Shanxi University, Taiyuan 030006, China; \\ liangwt@sxu.edu.cn \\ 3 Shanghai Advanced Research Institute, Chinese Academy of Science, Shanghai 201210, China; \\ yangyf@shanghaitech.edu.cn \\ * Correspondence: wuwanhua@scu.edu.cn (W.W.); wenk@sari.ac.cn (K.W.); yangchengyc@scu.edu.cn (C.Y.); \\ Tel.: +86-28-8541-6298 (C.Y.)
}

Received: 16 May 2019; Accepted: 4 June 2019; Published: 9 June 2019

check for updates

\begin{abstract}
Butoxycarbonyl (Boc)-protected pillar[4]arene[1]-diaminobenzene (BP) was synthesized by introducing the Boc protection onto the A1/A2 positions of BP. The oxygen-through-annulus rotation was partially inhibited because of the presence of the middle-sized Boc substituents. We succeeded in isolating the enantiopure $R_{P}\left(R_{P}, R_{P}, R_{P}, R_{P}\right.$, and $\left.R_{P}\right)$ - and $S_{P}\left(S_{P}, S_{P}, S_{P}, S_{P}\right.$, and $\left.S_{P}\right)$-BP, and studied their circular dichroism (CD) spectral properties. As the Boc substituent is not large enough to completely prevent the flip of the benzene units, enantiopure BP-f1 underwent racemization in solution. It is found that the racemization kinetics is a function of the solvent and temperature employed. The chirality of the BP-f1 could be maintained in n-hexane and $\mathrm{CH}_{2} \mathrm{Cl}_{2}$ for a long period at room temperature, whereas increasing the temperature or using solvents that cannot enter into the cavity of BP-f1 accelerated the racemization of BP-f1. The racemization kinetics and the thermodynamic parameters of racemization were studied in several different organic solvents.
\end{abstract}

Keywords: pillar[5]arene; planar chirality; chiral resolution; racemization kinetics; supramolecular chemistry

\section{Introduction}

Chiral macrocyclic molecules have attracted significant attention, because they are highly promising in applications for chiral induction [1-3], molecular recognition [4-6], and asymmetric catalysis [7-9]. A great number of macrocyclic compounds have been developed for the purpose of studying their optical properties [10-12]. Recently, the chirality of a novel emerging host molecule, pillar[n]arenes, has attracted increasing attention [13-16]. Pillar[n]arenes are macrocyclic compounds that are composed of several hydroquinone ether units and are featured by the well-defined cavity, unique host-guest complexation properties, and readily chemical functionalization. Normal pillar[5]arenes have two enantiomeric conformers with all hydroquinone ether units adapting a planar chiral $R_{p},\left(R_{p}, R_{p}, R_{p}\right.$, $R_{p}$, and $\left.R_{p}\right)$ or $S_{p},\left(S_{p}, S_{p}, S_{p}, S_{p}\right.$, and $\left.S_{p}\right)$ configuration. In general, these two conformers are rapidly interconvertible in a solution by flipping the ring units around the methylene bridges, the so-called oxygen-through-annulus rotation [17]. The inhibition of the oxygen-through-annulus rotation will lead to a pair of planar-chiral enantiomers. Three approaches, including rotaxanation, the introduction of a side ring into one ring unit, as well as the chemical modification of bulky groups onto the rims, have been exploited for constructing chiral pillar[5]arenes [18-20]. Bulky groups, such as cyclohexylmethyl, phenyl, 
or bithienyl groups, have been chemically grafted onto one or more hydroquinone ether units, and the oxygen-through-annulus rotation was restrained or completely stopped [21,22]. It occurred to us that if introducing a group of suitable size, the oxygen-through-annulus could still be allowed, but the rotation velocity is slowed down. This will then provide a powerful tool to study the effect of the external factors, such as the temperature and solvent, on the rotational kinetics of pillar[5]arene. Herein, we report on the successful isolation of butoxycarbonyl (Boc)-protected pillar[4]arene-[1]diaminobenzene (BP) planar chiral enantiomers. Two middle-sized Boc-protected substituents on the A1/A2 positions significantly decelerated the flip of pillar[5]arene, to allow for the racemization of BP with an observable velocity. The thermodynamics and kinetics of the racemization were investigated under different solvent and temperature conditions, which may serve as a guideline in the isolation and control of the enantiomeric conformations of pillar[n]arenes by manipulating the external factors.

\section{Materials and Methods}

All of the compounds and reagents were obtained from commercial suppliers and were used as received. Chiral analytical HPLC was performed with a Chiralpak IA column $(0.46 \times 25 \mathrm{~cm})$ by a Shimadzu LC Prominence 20 HPLC instrument (Shimadzu, Tokyo, Japan) equipped with a UV-VIS detector (conditions: injection volume: $20 \mu \mathrm{L}$ of rac-BP $(0.2 \mathrm{mM})$; mobile phase: hexane/dichloromethane, $70 / 30(v / v)$; flow rate: $1.0 \mathrm{~mL} / \mathrm{min}$ at $20{ }^{\circ} \mathrm{C}$; retention time $\left(t_{\mathrm{R}}\right): 5.3 \mathrm{~min}$ for BP-f1, $5.7 \mathrm{~min}$ for BP-f2). Preparative column chromatography was carried out with a Chiralpak IA column $(1.0 \times 25 \mathrm{~cm})$ by a recycling preparative HPLC LC9210NEXT instrument (JAI, Tokyo, Japan) equipped with a UV-VIS detector (conditions: injection volume: $3 \mathrm{~mL}$ of rac-BP $(2 \mathrm{mM})$; mobile phase: hexane/dichloromethane, $70 / 30(v / v)$; flow rate: $4.0 \mathrm{~mL} / \mathrm{min}$ at $20^{\circ} \mathrm{C}$; retention time $\left(t_{R}\right): 11.4 \mathrm{~min}$ for BP-f1, $12.5 \mathrm{~min}$ for BP-f2). The circular dichroism spectra were measured by using a JASCO J-1500 spectrometer (Jasco, Tokyo, Japan) equipped with a Unisoku cryostat, and $\theta$ values are given in units of mdeg.

\section{Results and Discussion}

Wang and coworkers have demonstrated that the tert-butoxycarbonyl (Boc) group, which has a relatively large size, can thread through the cavity of pillar[5]arene when tethered on a chain [23]. We proposed that if the Boc group is linked directly on one benzene ring of pillar[5]arene, the rotation of the ring units should be vert decelerated because of the steric inhibition of Boc. To prove this, Boc-protected pillar[4]-arene[1]diaminobenzene (BP), in which one of the hydroquinone units was replaced by phenylenediamine and the two amino groups were protected by Boc, were prepared according to the reported procedures (Scheme 1) [24].

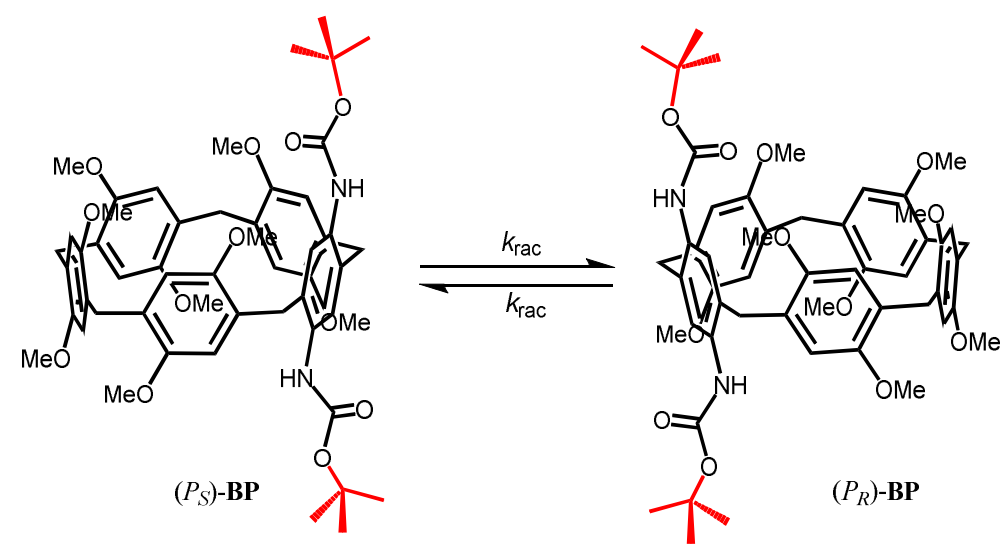

Scheme 1. The chemical structure of the planar chiral butoxycarbonyl (Boc)-protected pillar[4]arene[1]-diaminobenzene. 
The chiral resolution of BP was carried out by preparative chiral-phase HPLC equipped with a chiral column (Chiralpak IA). The enantiomers of BP were successfully resolved into two fractions, BP-f1 and BP-f2, with the retention time of $5.3 \mathrm{~min}$ and $5.7 \mathrm{~min}$, respectively, eluted with a mixture of hexane and dichloromethane at $20^{\circ} \mathrm{C}$ (Figure 1a). On the basis of the enantiomer peak integrations, each separated enantiomer was determined to have a purity of $>99 \%$.

The geometries of $\left(P_{\mathrm{S}}\right)$-BP and $\left(P_{\mathrm{R}}\right)$-BP were optimized using density functional theory (DFT), and the optimized structures and their energies are given in Scheme 2. In the optimized structures of the both enantiomers, the bulky tert-butoxy carbonyl group was located outside the electron rich aromatic cavity, because of steric hindrance. Interestingly, the DFT results show that the energies of the both $\left(P_{\mathrm{S}}\right)$-BP and $\left(P_{\mathrm{R}}\right)$-BP are same, and the accompanying racemization are feasible and or equilibrated easily at room temperature.

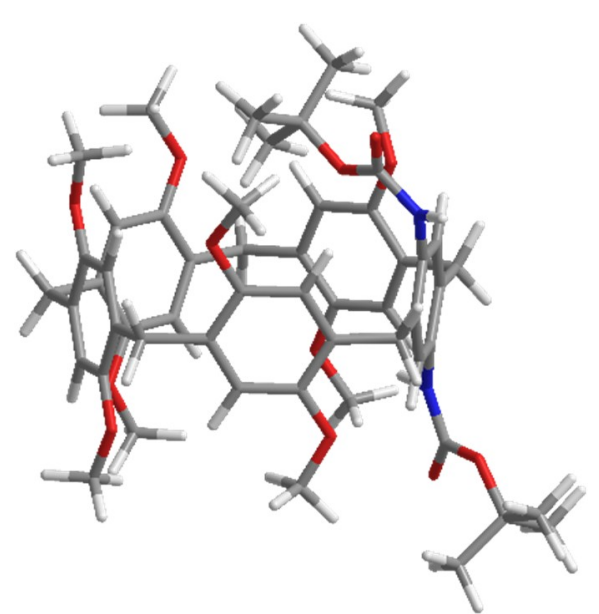

(a)

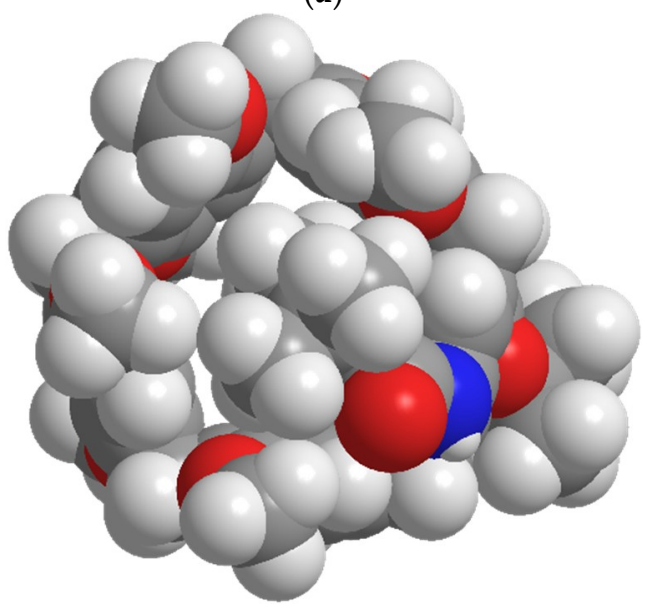

(c)

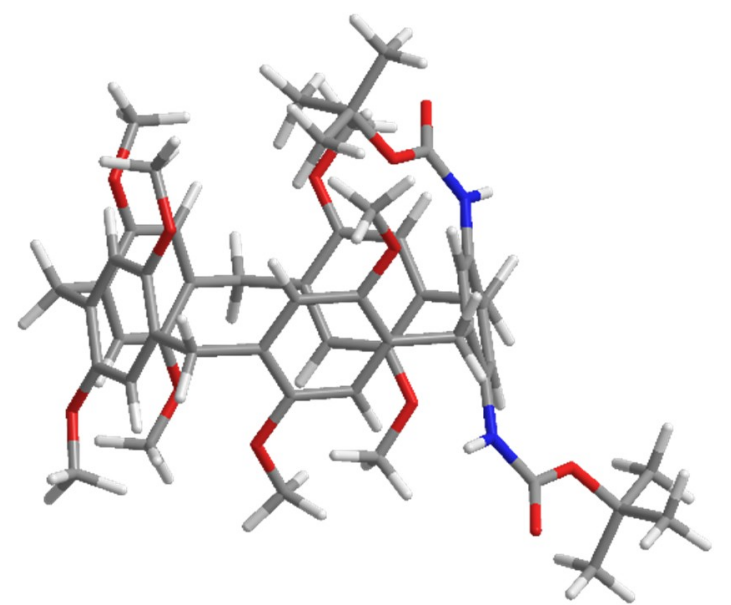

(b)

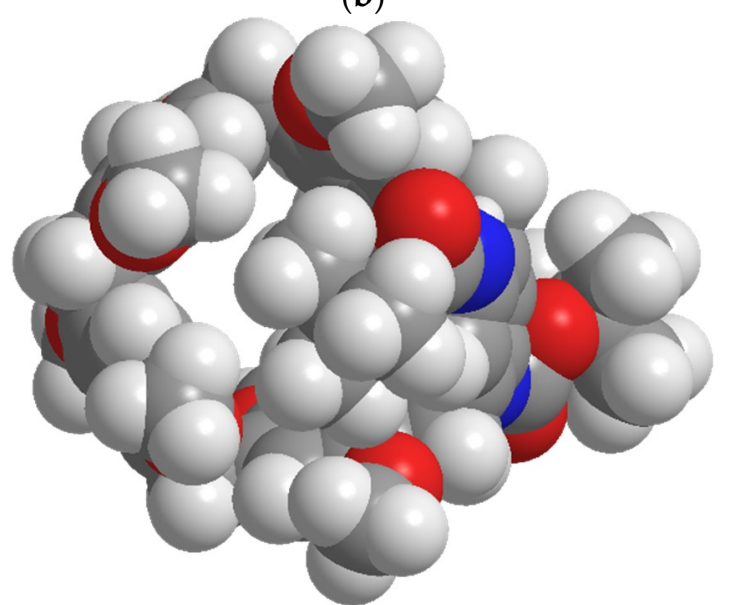

(d)

Scheme 2. Optimized geometries of $\left(P_{R}\right)-(\mathbf{B P})$ and $\left(P_{S}\right)$-BP: $(\mathbf{a})$ and $(\mathbf{b})$ are the side views of the stick model, respectively, and (c) and (d) are the top views of space filling models, respectively. The geometries were optimized by the Gaussian 09 program using the basic set DFT/RB3LYP/6-31G(d) method.

As shown in Figure 2, the fraction firstly eluted from the column (BP-f1) showed a strong negative circular dichroism extreme $\left(\mathrm{CD}_{\mathrm{ex}}\right)$ at ca $309 \mathrm{~nm}$, and a positive $C D$ signal at $262.5 \mathrm{~nm}$. The fraction secondly eluted from the column (BP-f2) provided a CD spectrum that is almost a perfect mirror image to that of BP-f1, and confirmed that BP-f1 and BP-f2 are a pair of enantiomers. We have demonstrated that the positive $\mathrm{CD}_{\mathrm{ex}}$ corresponds to the $R_{p}$ configuration of pillar[5]arene, and vice versa for the $S_{p}$ configuration [20], which allowed us to confirm that BP-f1 and BP-f2 are the $S_{p}$ and $R_{p}$ enantiomers, respectively. 


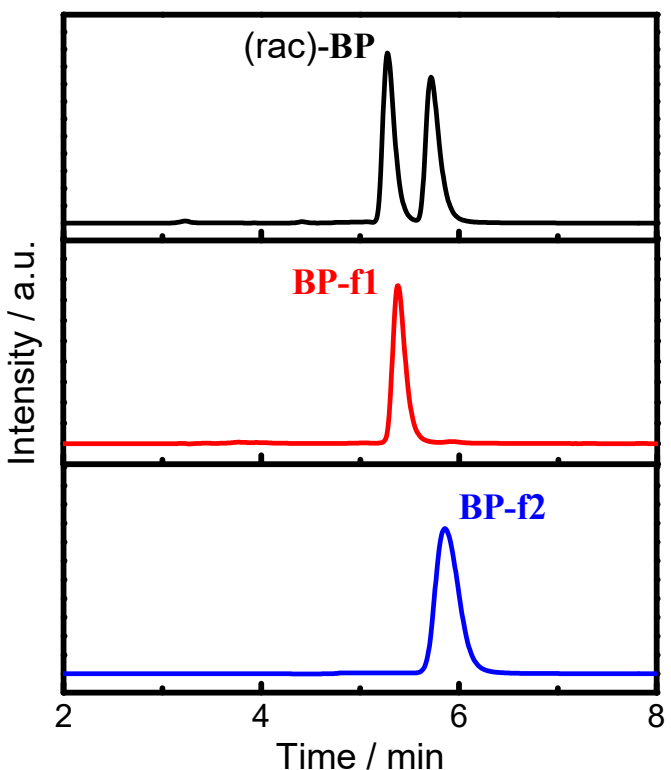

(a)

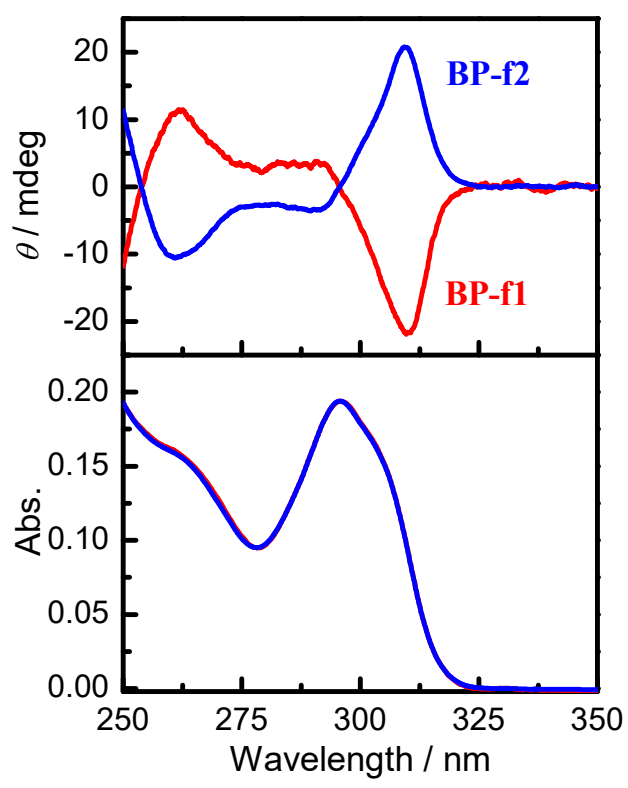

(b)

Figure 1. (a) Chiral HPLC traces of (rac)-pillar[4]arene[1]-diaminobenzene (BP), and resolved BP-f1 and BP-f2, detected by UV at $295 \mathrm{~nm}$ (conditions: column: DAICEL Chiralpak IA; mobile phase: hexane $/$ dichloromethane $=70 / 30$; flow rate $=1.0 \mathrm{~mL} / \mathrm{min}$; temperature: $20{ }^{\circ} \mathrm{C}$; retention time $\left(t_{\mathrm{R}}\right)$ : $5.3 \mathrm{~min}$ for BP-f1, $5.7 \mathrm{~min}$ for BP-f2). (b) Circular dichroism and UV-VIS spectra of $10 \mu \mathrm{M}$ BP-f1 (red) and BP-f2 (blue) measured in $\mathrm{CHCl}_{3}$ at $20^{\circ} \mathrm{C}$.

The direct linkage of Boc on the ring unit should cause a considerable steric effect and will retard the flipping kinetics, which was confirmed by the successful chiral resolution of BP. On the other hand, as the Boc moiety can readily enter into the cavity of pillar[5]arene, it seems reasonable to expect that the rotation of the ring units will not be completely inhibited by the presence of Boc. To prove this hypothesis, the CD spectral behavior of enantiopure BP-f1 were investigated in different solvents. Indeed, the time-dependent CD spectra of BP-f1 demonstrated that BP-f1 underwent racemization in the solution at room temperature, which is highly solvent dependent. As illustrated in Figure 2a, the CD spectra of BP-f1 in methylcyclohexane were gradually decreased at $25^{\circ} \mathrm{C}$ with time, leading to a complete fading of the $\mathrm{CD}$ signals. In $\mathrm{CHCl}_{3}$, a decrease of the $\mathrm{CD}$ signals was also observed, however, this was much slower than that in methylcyclohexane (Figure 2b). An even slower decrease was seen with $\mathrm{CH}_{2} \mathrm{Cl}_{2}$, which showed only a little decrease after remaining at $25^{\circ} \mathrm{C}$ for two hours (Figure 2c). Such a critical dependence on the solvents promoted us to study the racemization kinetics in different solvents.

The $C D_{\text {ex }}$ value changes at $309 \mathrm{~nm}$ as a function of time was measured in different solvents and temperatures. As exemplified in Figure $3 a$, the $\mathrm{CD}_{\text {ex }}$ values in hexane at $25^{\circ} \mathrm{C}$ hardly changed after $3000 \mathrm{~s}$, demonstrating very slow racemization kinetics in hexane. Slow racemization kinetics were also observed in $\mathrm{CH}_{2} \mathrm{Cl}_{2}$ (Figure A6). The plots of $\ln \left(\theta_{0} / \theta_{t}\right)$ against time gave straight lines, supporting the first-order kinetic model [25]. Increasing the temperature usually increases the reaction kinetics, and we have demonstrated that the temperature is critical for affecting the molecular recognition and stereoselectivity of supramolecular photochirogenesis [26-33]. To understand the temperature effect on the racemization of BP-f1, the $\mathrm{CD}_{\mathrm{ex}}$ versus time was recorded at different temperatures. Indeed, the decrease of $C D_{\text {ex }}$ became apparent with the temperature, indicating accelerated racemization at higher temperatures. The racemization rate constants, $k_{r a c}$, calculated based on the first-order reaction kinetics $[25,34,35]$, are $2.02 \times 10^{-7} \mathrm{~s}^{-1}$ at $25^{\circ} \mathrm{C}, 2.22 \times 10^{-6} \mathrm{~s}^{-1}$ at $35^{\circ} \mathrm{C}, 4.44 \times 10^{-6} \mathrm{~s}^{-1}$ at $40{ }^{\circ} \mathrm{C}, 1.34 \times 10^{-5} \mathrm{~s}^{-1}$ at $45{ }^{\circ} \mathrm{C}$, and $5.39 \times 10^{-5} \mathrm{~s}^{-1}$ at $55{ }^{\circ} \mathrm{C}$, respectively. On the basis of the Eyring equation (Appendix A), the thermodynamic parameters were obtained. As shown in Figure 4, 
$\Delta G^{\ddagger}=109.65 \mathrm{~kJ} \mathrm{~mol}^{-1}, \Delta H^{\ddagger}=131.83 \mathrm{~kJ} \mathrm{~mol}^{-1}$, and $\Delta S^{\ddagger}=74.39 \mathrm{~J} \mathrm{~mol}^{-1}$ were obtained in n-hexane. In dichloromethane, the $\mathrm{CD}$ signal is hardly changed, even it was heated to $35^{\circ} \mathrm{C}$, which is close to the dichloromethane boiling point (Figure A6).

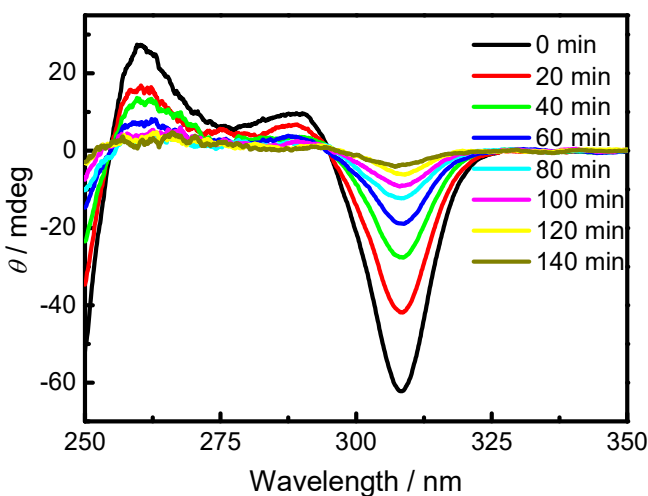

(a)

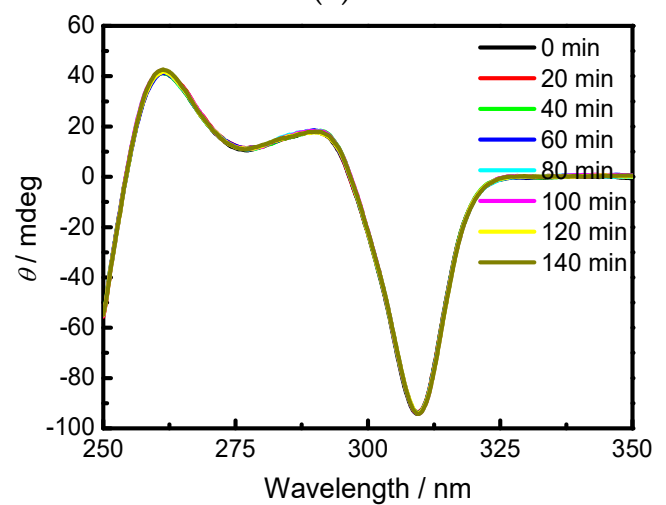

(c)

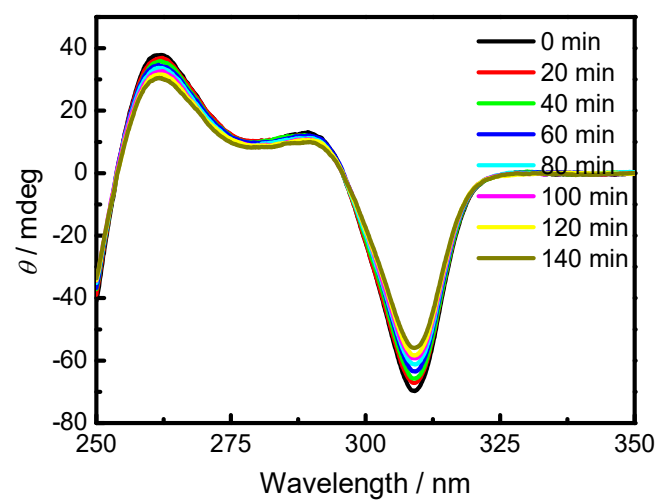

(b)

Figure 2. (a) Circular dichroism (CD) spectra of $34.6 \mu \mathrm{M}$ BP-f1 in methylcyclohexane at $298.15 \mathrm{~K}$; (b) CD spectra of $34.6 \mu \mathrm{M}$ BP-f1 in $\mathrm{CHCl}_{3}$ at $298.15 \mathrm{~K}$; (c) CD spectra of $34.6 \mu \mathrm{M} \mathrm{BP-f1}$ in $\mathrm{CH}_{2} \mathrm{Cl}_{2}$ at $298.15 \mathrm{~K}$.

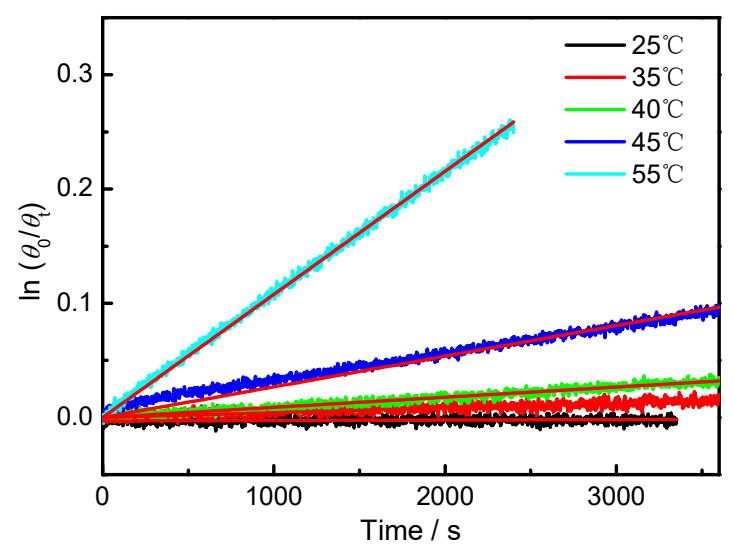

(a)

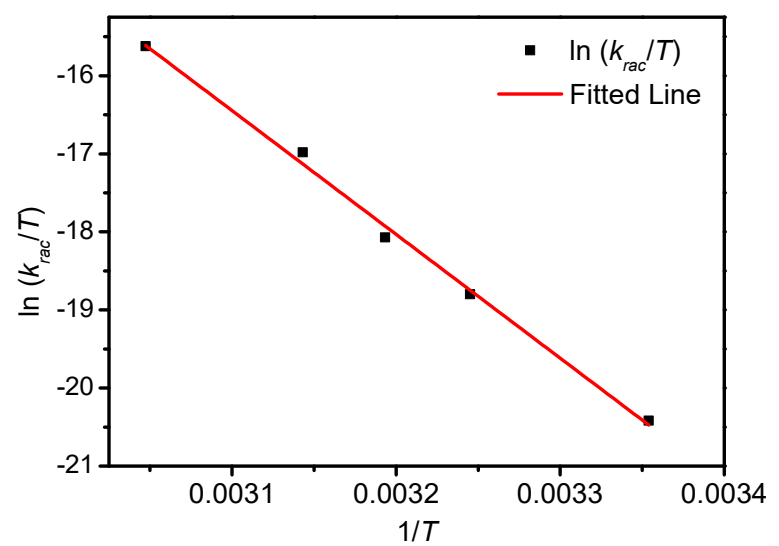

(b)

Figure 3. (a) Plot of $\ln \left(\theta_{0} / \theta_{t}\right)$ against time, of BP-f1 in n-hexane measured at $25^{\circ} \mathrm{C}$ (black), $35^{\circ} \mathrm{C}$ (red), $40{ }^{\circ} \mathrm{C}$ (green), $45^{\circ} \mathrm{C}$ (blue), and $55^{\circ} \mathrm{C}$ (light blue). The red lines represent the linear least squares fitting curves by assuming that the racemization follows a first-order reaction kinetics. (b) Eyring plots for the racemization of $\mathbf{B P}-\mathbf{f 1}$ in $\mathbf{n}$-hexane. 
To explore the effect of the solvent on the racemization rate, the time dependence of $C_{\text {ex }}$ in different solvents was monitored. As illustrated in Figure 4, much faster racemization kinetics were observed in other solvents, such as methylcyclohexane, cyclohexane, and $\mathrm{MeOH}$. While in DCM, $\mathrm{CH}_{3} \mathrm{CN}$ and $\mathrm{CHCl}_{3}, \mathbf{B P}$-f1 also showed slow racemization rates. Based on the first order kinetics, the $k_{r a c}$ values and the half-lifetimes at $25^{\circ} \mathrm{C}$ were calculated and are listed in Table 1 . It turned out that BP-f1 afforded the smallest $k_{\text {rac }}$ value $\left(2.02 \times 10^{-7}\right)$ in n-hexane, having a long half-lifetime of 19.9 days. A similar slow racemization was also observed in $\mathrm{CH}_{2} \mathrm{Cl}_{2}\left(k_{r a c}=6.23 \times 10^{-7}\right)$. The $k_{\text {rac }}$ values increased in the order of n-hexane $<\mathrm{CH}_{2} \mathrm{Cl}_{2}<\mathrm{CH}_{3} \mathrm{CN}<\mathrm{CHCl}_{3}<$ methylcyclohexane $<$ cyclohexane $<$ $\mathrm{MeOH}$, showing a 1564 times acceleration in $\mathrm{MeOH}$ compared with that in hexane. In $\mathrm{MeOH}$, a short half-lifetime of $18.3 \mathrm{~min}$ was reckoned. Such solvent-dependent kinetics are apparently not simply due to the polarity of the solvent, as methylcyclohexane, cyclohexane, and hexane are all nonpolar solvents (Table 1), but showed drastically different $k_{\text {rac }}$ values. However, it could be reasonably accounted for by the host-guest complexation between the pillar[5]arene and solvent molecules involved in the racemization process. The inclusion of n-hexane, $\mathrm{CH} 2 \mathrm{Cl} 2$, and $\mathrm{CH} 3 \mathrm{CN}$ into the cavity of pillar[5]arenes has been characterized by single X-ray crystalline and NMR analysis [15,36-38]. The oxygen-through-annulus rotation will be blocked when the solvent molecule is located in the cavity of pillar[5]arene, and the racemization kinetics will be significantly decelerated by the complexation of the solvent molecules. This observation is a good explanation for why we get successful chiral resolution only when using a mixture of $\mathrm{CH}_{2} \mathrm{Cl}_{2}$ and hexane as the eluent.

On the other hand, methylcyclohexane and cyclohexane are too big to be accommodated by the cavity, and will primarily not interfere with the racemization of BP-f1. The slightly slower racemization found in methylcyclohexane relative to that in cyclohexane is presumably due to the weak interaction of the methyl group in methylcyclohexane with pillar[5]arene [39]. It is slightly unexpected that BP-f1 showed the fastest racemization kinetics in $\mathrm{MeOH}$, which has a small size and thus is possible to enter into the cavity of pillar[5]arene. We speculate that $\mathrm{MeOH}$ can destroy the hydrogen bond of $\mathrm{NH}$ and the oxygen atom of adjacent units, and therefore can significantly improve the racemization kinetics of BP-f1.

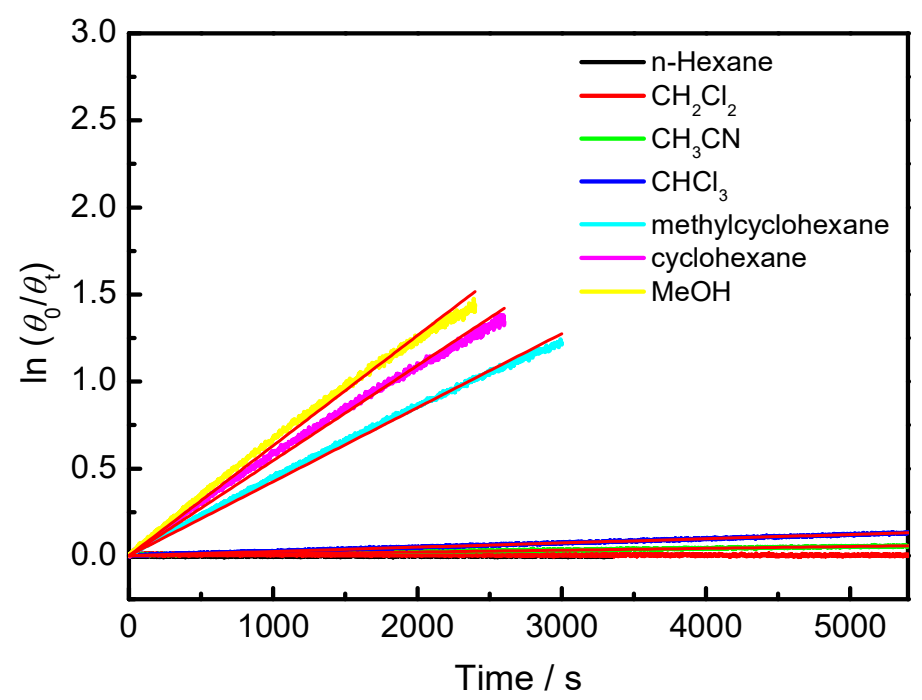

Figure 4. Plot of $\ln \left(\theta_{0} / \theta_{t}\right)$ against time of BP-f1 in in various solvents at $25^{\circ} \mathrm{C}$. 
Table 1. The rate constants of racemization $\left(k_{\text {rac }}\right)$ and the estimated half-lives (t1/2) of pillar[4]arene[1]diaminobenzene (BP)-f1. 1 .

\begin{tabular}{cccc}
\hline Solvent & $\mathbf{E}_{\mathbf{T}} / \mathbf{( k c a l ~ m o l}^{\mathbf{- 1}} \mathbf{~}^{\mathbf{2}}$ & $\boldsymbol{k}_{\text {rac }} / \mathbf{( s}^{\mathbf{- 1})^{3}}$ & $\mathbf{t}_{\mathbf{1} / \mathbf{2}}$ \\
\hline n-Hexane & 31.0 & $2.02 \times 10^{-7}$ & $19.9 \mathrm{~d}$ \\
$\mathrm{CH}_{2} \mathrm{Cl}_{2}$ & 41.1 & $4.78 \times 10^{-7}$ & $8.4 \mathrm{~d}$ \\
$\mathrm{CH}_{3} \mathrm{CN}$ & 46.0 & $5.25 \times 10^{-6}$ & $18.3 \mathrm{~h}$ \\
$\mathrm{CHCl}_{3}$ & 39.1 & $1.22 \times 10^{-5}$ & $7.9 \mathrm{~h}$ \\
methylcyclohexane & - & $2.12 \times 10^{-4}$ & $27.2 \mathrm{~min}$ \\
cyclohexane & 30.9 & $2.73 \times 10^{-4}$ & $21.2 \mathrm{~min}$ \\
MeOH & 55.4 & $3.16 \times 10^{-4}$ & $18.3 \mathrm{~min}$ \\
\hline nts were carried out at $298.15 \mathrm{~K} .^{2}$ Reichardt's solvent polarity parameter [40]. ${ }^{3}$ The racemization
\end{tabular}
${ }^{1}$ The experiments were carried out at $298.15 \mathrm{~K} .{ }^{2}$ Reichardt's solvent polarity parameter [40]. ${ }^{3}$ The racemization
rate constant.

The temperature-dependent racemization kinetics of BP-f1 were investigated in different solvents. Enantiopure BP-f1 was heated to different temperatures, and the time course of $C D_{\text {ex }}$ was recorded (Appendix B). The racemization rate constants at different temperatures were obtained by linear regression analyses. The Eyring analysis by plotting $\ln \left(k_{\text {rac }} / T\right)$ as a function of $1 / T$ showed good linear relationships (Appendices $B$ and $C$ ), and the active enthalpy changes $\left(\Delta H^{\ddagger}\right)$ and entropy changes $\left(\Delta S^{\ddagger}\right)$ were obtained from the slope and intercept, respectively. Table 2 lists the active thermodynamic parameters of the racemization of BP-f1 in the six solvents. Large positive active enthalpies were observed in all of the solvents. The relatively smaller active enthalpy could be accounted for in the context that the hydrogen bonds in BP-f1 were broken by the methanol. In most solvents, negative entropy changes were observed, except for $n$-hexane and methylcyclohexane. This is possibly due to the release of the included or partially included solvent molecule when BP-f1 flipping to change the conformer to BP-f2.

Table 2. Thermodynamic parameters for racemization of BP-f1.

\begin{tabular}{cccc}
\hline Solvent & $\boldsymbol{\Delta} \boldsymbol{G}^{\ddagger} \mathbf{1} /\left(\mathbf{k J} / \mathbf{m o l}^{-\mathbf{1})}\right.$ & $\boldsymbol{\Delta} \boldsymbol{H}^{\ddagger} / \mathbf{( k J} / \mathbf{m o l}^{-\mathbf{1})}$ & $\boldsymbol{\Delta} \boldsymbol{S}^{\ddagger} /\left(\mathbf{J} / \mathbf{m o l}^{-\mathbf{1})}\right.$ \\
\hline n-Hexane & 109.65 & 131.83 & 74.39 \\
$\mathrm{CH}_{3} \mathrm{CN}$ & 103.15 & 81.02 & -74.21 \\
$\mathrm{CHCl}_{3}$ & 101.03 & 93.34 & -25.79 \\
methylcyclohexane & 94.21 & 97.54 & 11.16 \\
cyclohexane & 93.23 & 87.93 & -17.79 \\
MeOH & 93.07 & 63.29 & -99.87 \\
\hline
\end{tabular}

${ }^{1}$ The data was carried out at $298.15 \mathrm{~K}$.

\section{Conclusions}

In conclusion, we have synthesized and successfully resoluted planar $\left(P_{R}\right)$ - and $\left(P_{S}\right)$-enantiomeric Boc-protected pillar[4]arene[1]diaminobenzene BP. The racemization kinetics of the chiral BP-f1 were studied. Hexane and $\mathrm{CH} 2 \mathrm{Cl} 2$ can maintain the enantiomeric forms of $\mathbf{B P}-\mathbf{f} \mathbf{1}$ for long periods, because of the complexation of the solvent molecules with the cavity of pillar[4]arene[1]diaminobenzene. The racemization process was accelerated by increasing the temperature or use the solvents that cannot thread into the cavity of BP or can destroy intramolecular hydrogen bond. The present study has provided, for the first time, thermodynamic parameters of the pillararenes in different solvents that will serve as an important guideline in studying the conformational properties of pillar[n]arenes.

Author Contributions: C.X. performed the experiments and analyzed the data. Y.Y. synthesized the compounds. W.W. and W.L. designed the experiments. K.K. analyzed the data. C.Y. and K.W. contributed for scientific guide and wrote the paper.

Funding: This research was funded by the National Natural Science Foundation of China (no. 21871194, 21572142, 21402129, and 21402110), the National Key Research and Development Program of China (no. 2017YFA0505903), and the Science and Technology Department of Sichuan Province (2017SZ0021). 
Conflicts of Interest: The authors declare no conflict of interest.

\section{Appendix A. General Procedure for the Monitoring Racemization of BP-f1}

The freshly prepared BP-f1 was dissolved in different solvents and subjected to the CD measurement immediately.

The observed time-dependent CD changes satisfied the first-order kinetics (Scheme 1), in which $k_{r a c}\left(\mathrm{~s}^{-1}\right)$ is the rate constant for the racemization. The linear regression analysis of the $\mathrm{CD}$ data gave the rate constants $\left(k_{r a c}\right)$. The half-life time $\left(\mathrm{t}_{1 / 2}\right)$ was obtained from Equation (A1), as follows:

$$
t_{\frac{1}{2}}=\frac{\ln 2}{2 k_{\text {rac }}}
$$

The obtained $k_{\text {rac }}$ values were analyzed according to the Eyring Equation (A2), as follows:

$$
\ln \left(k_{\text {rac }} / T\right)=\Delta S^{\ddagger} / R-\ln \left(h / k_{\mathrm{B}}\right)-\Delta H^{\ddagger} / R T
$$

in which $h$ is the Planck's constant, $k_{\mathrm{B}}$ is the Boltzmann constant, $R\left(8.314 \mathrm{~J} \mathrm{~K}^{-1} \mathrm{~mol}^{-1}\right)$ is the gas constant, $T(\mathrm{~K})$ is the absolute temperature, $\Delta H^{\ddagger}$ is the enthalpy of activation, and $\Delta S^{\ddagger}$ is the entropy of activation.

\section{Appendix B.}

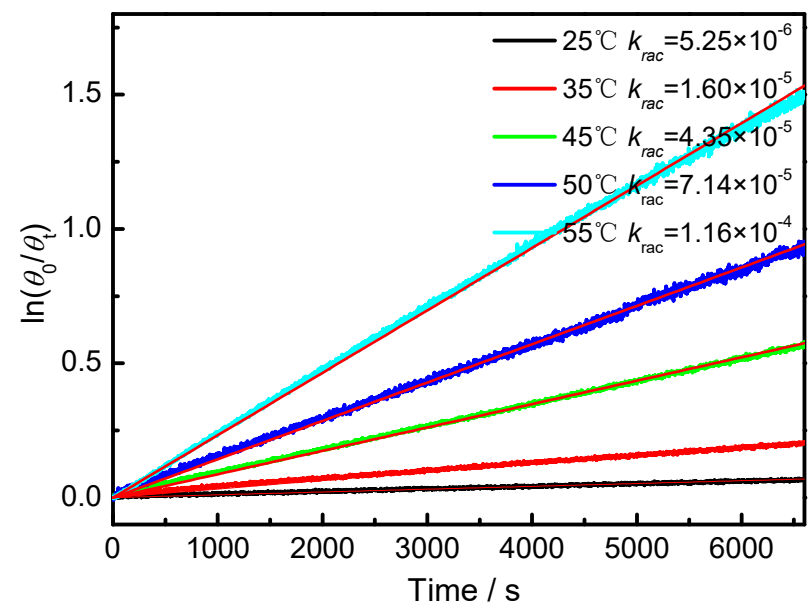

Figure A1. Plot of $\ln \left(\theta_{0} / \theta_{\mathrm{t}}\right)$ against time of $\mathbf{B P}-\mathbf{f 1}$ in $\mathrm{CH}_{3} \mathrm{CN}$.

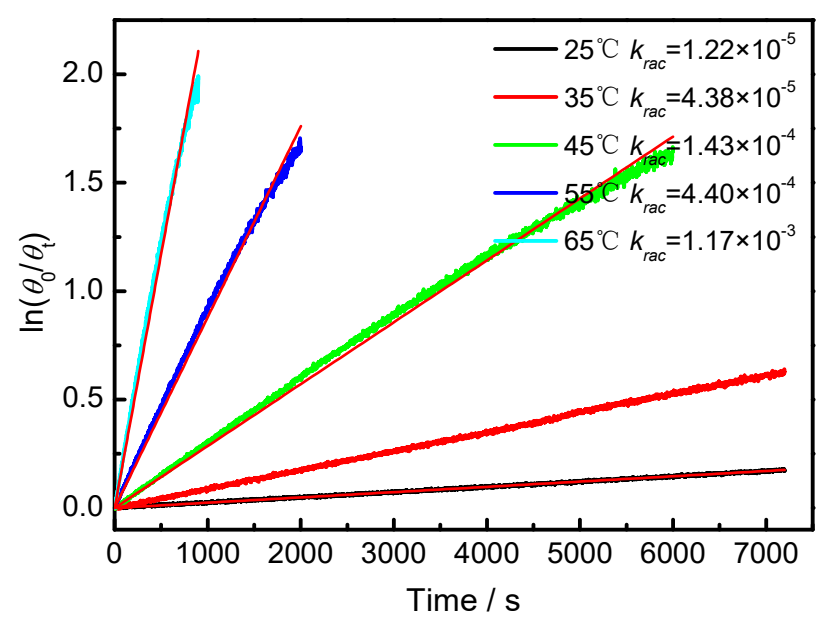

Figure A2. Plot of $\ln \left(\theta_{0} / \theta_{\mathbf{t}}\right)$ against time of $\mathbf{B P}-\mathbf{f} \mathbf{1}$ in $\mathrm{CHCl}_{3}$. 


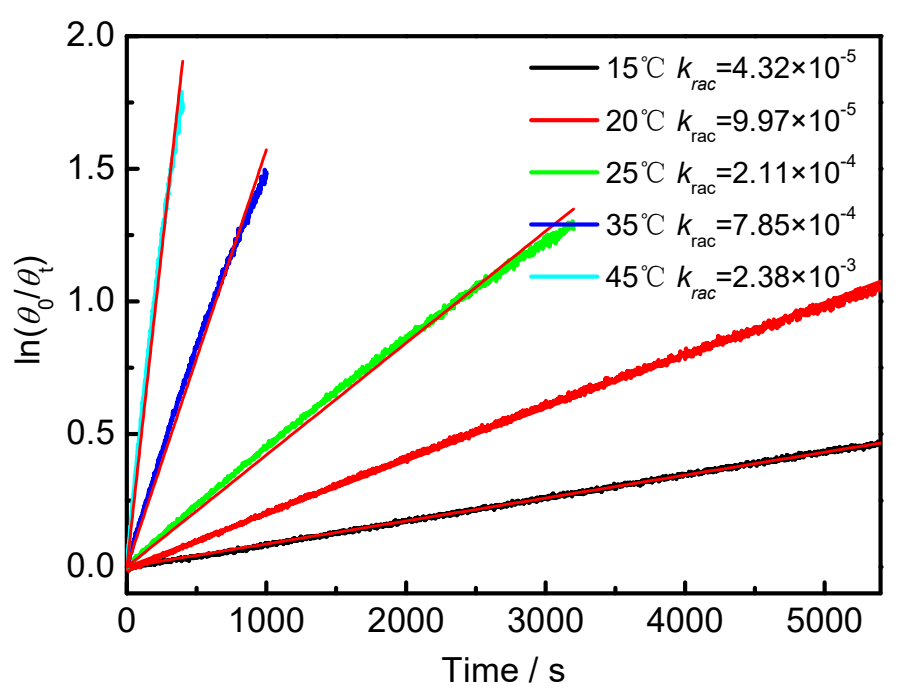

Figure A3. Plot of $\ln \left(\theta_{0} / \theta_{\mathbf{t}}\right)$ against time of $\mathbf{B P}-\mathbf{f} \mathbf{1}$ in $\mathrm{MCH}$.

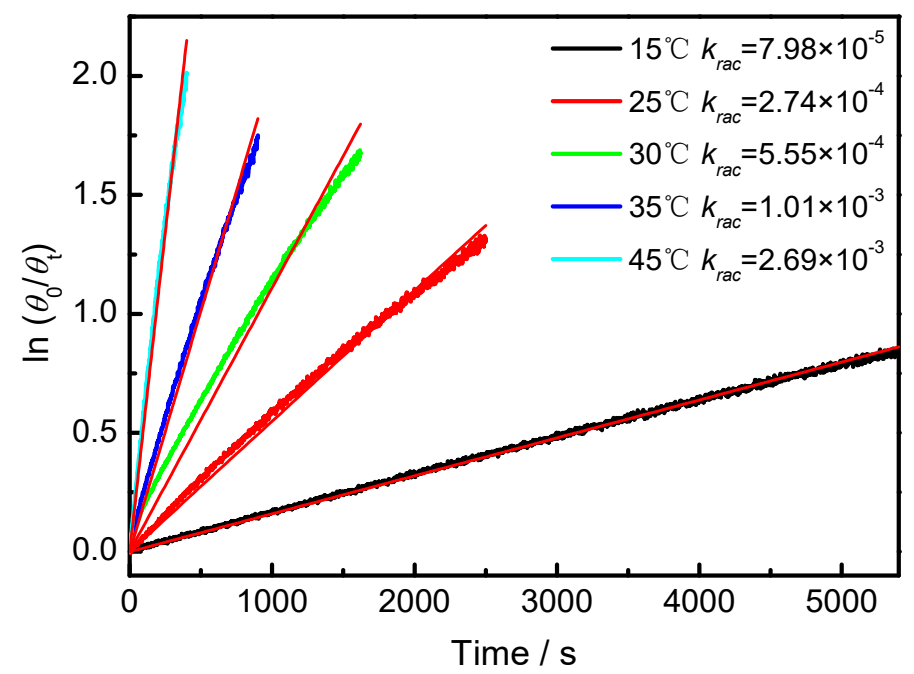

Figure A4. Plot of $\ln \left(\theta_{0} / \theta_{\mathrm{t}}\right)$ against time of BP-f1 in CYH.

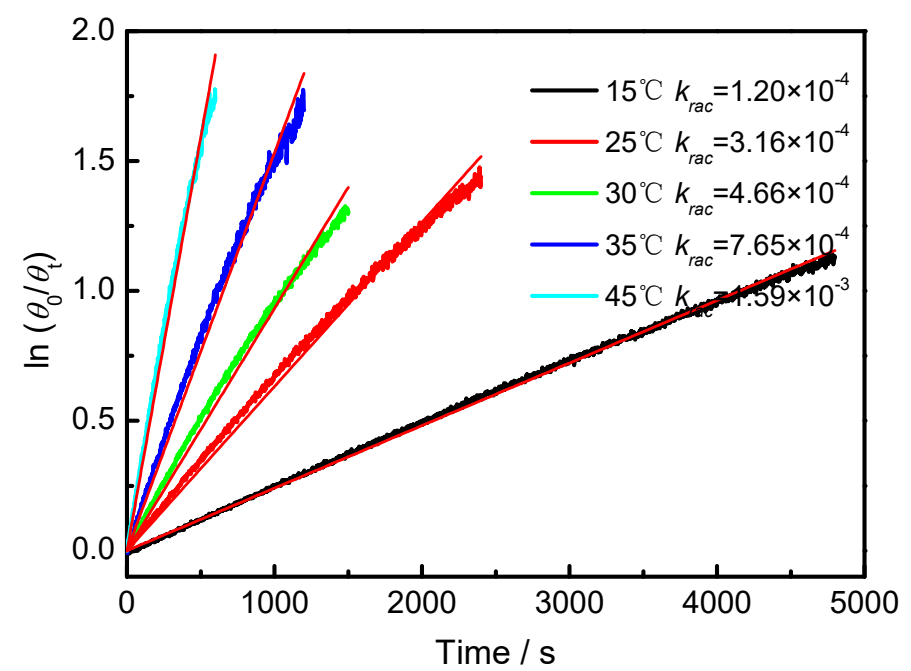

Figure A5. Plot of $\ln \left(\theta_{0} / \theta_{\mathbf{t}}\right)$ against time of BP-f1 in $\mathrm{MeOH}$. 


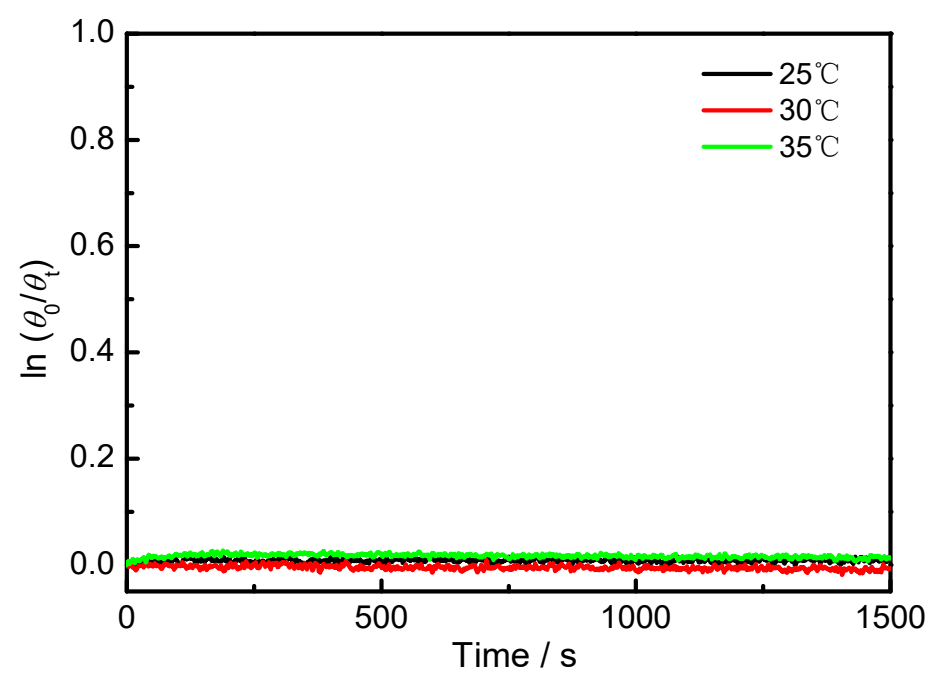

Figure A6. Plot of $\ln \left(\theta_{0} / \theta_{t}\right)$ against time of BP-f1 in $\mathrm{CH}_{2} \mathrm{Cl}_{2}$.

Appendix C.

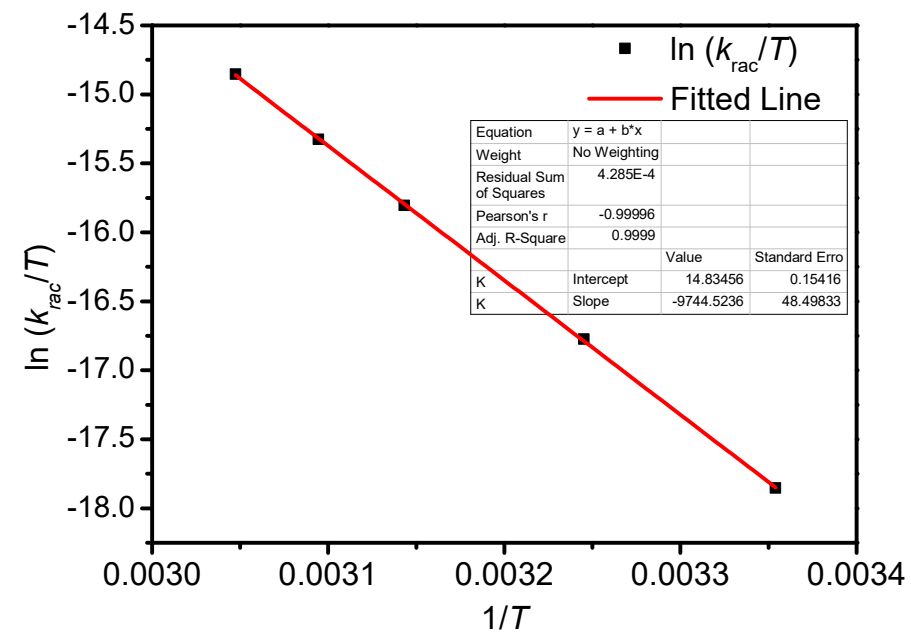

Figure A7. Eyring plots for the racemization of BP-f1 in $\mathrm{CH}_{3} \mathrm{CN}$.

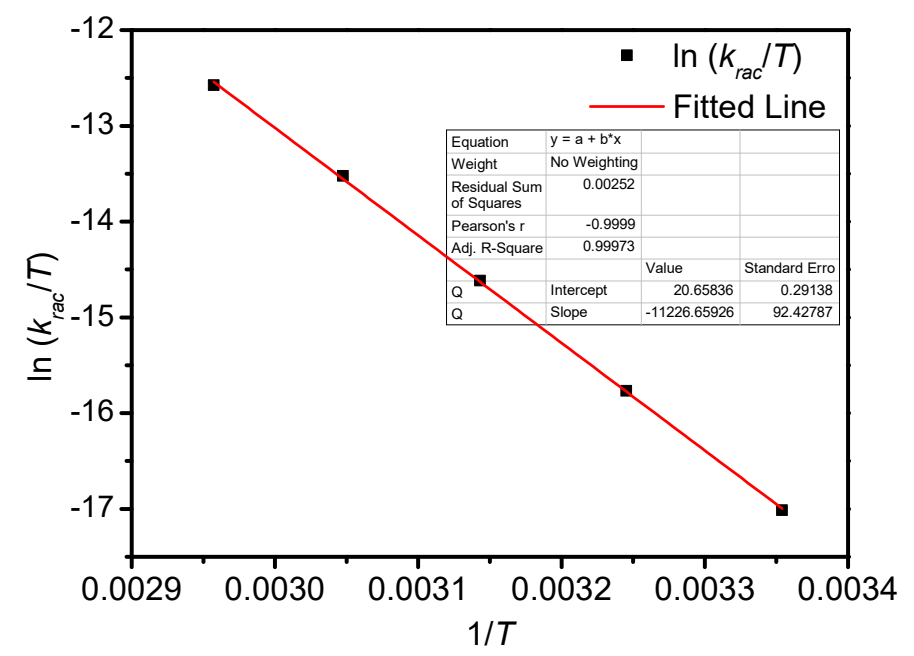

Figure A8. Eyring plots for the racemization of $\mathbf{B P - f 1}$ in $\mathrm{CHCl}_{3}$. 


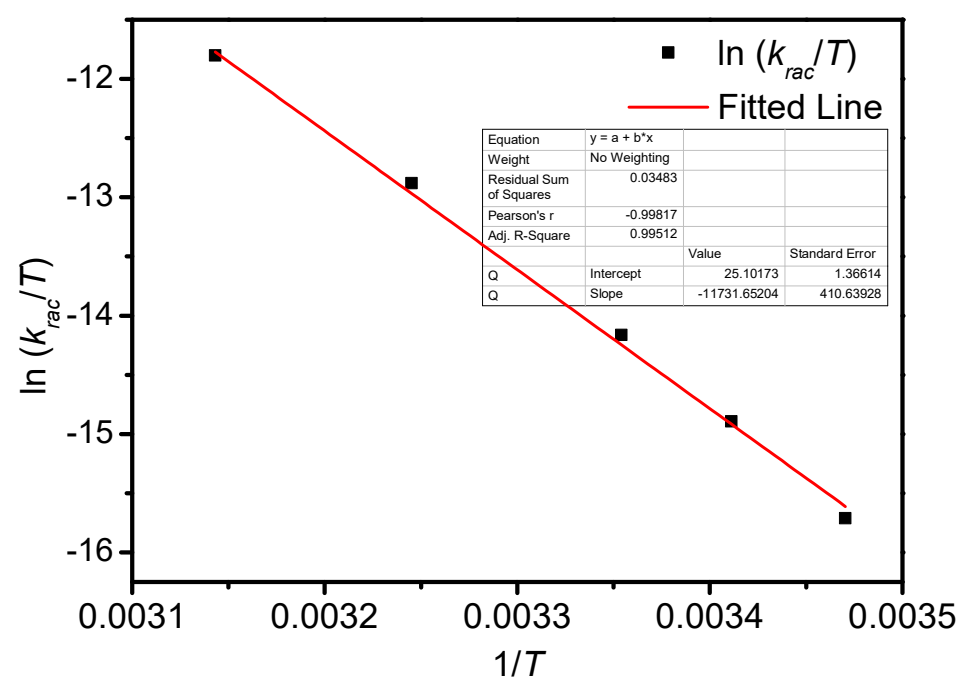

Figure A9. Eyring plots for the racemization of $\mathbf{B P}-\mathbf{f 1}$ in $\mathrm{MCH}$.

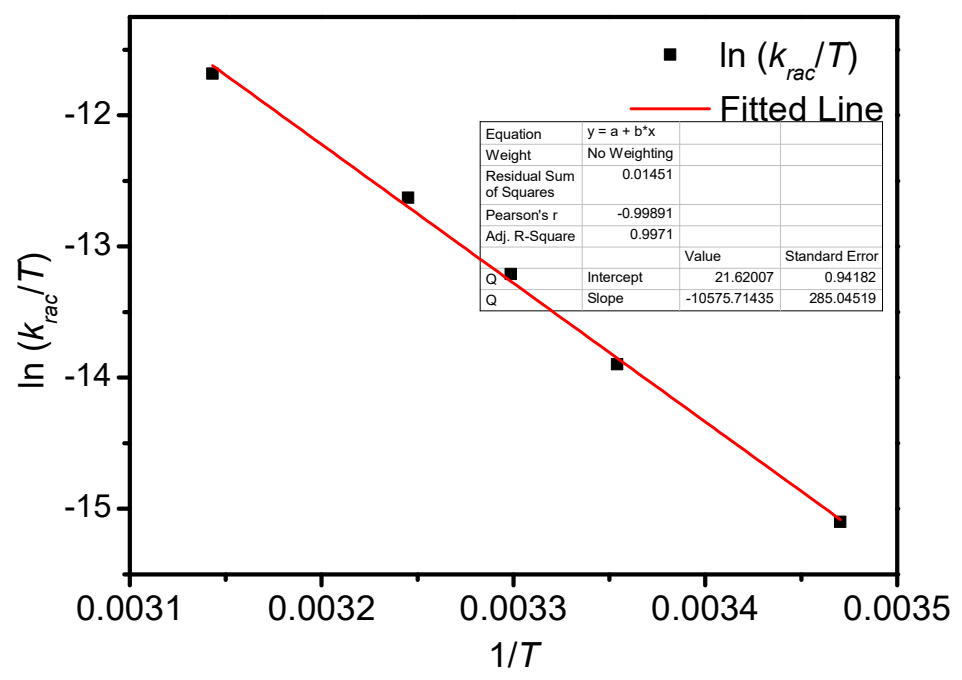

Figure A10. Eyring plots for the racemization of BP-f1 in CYH.

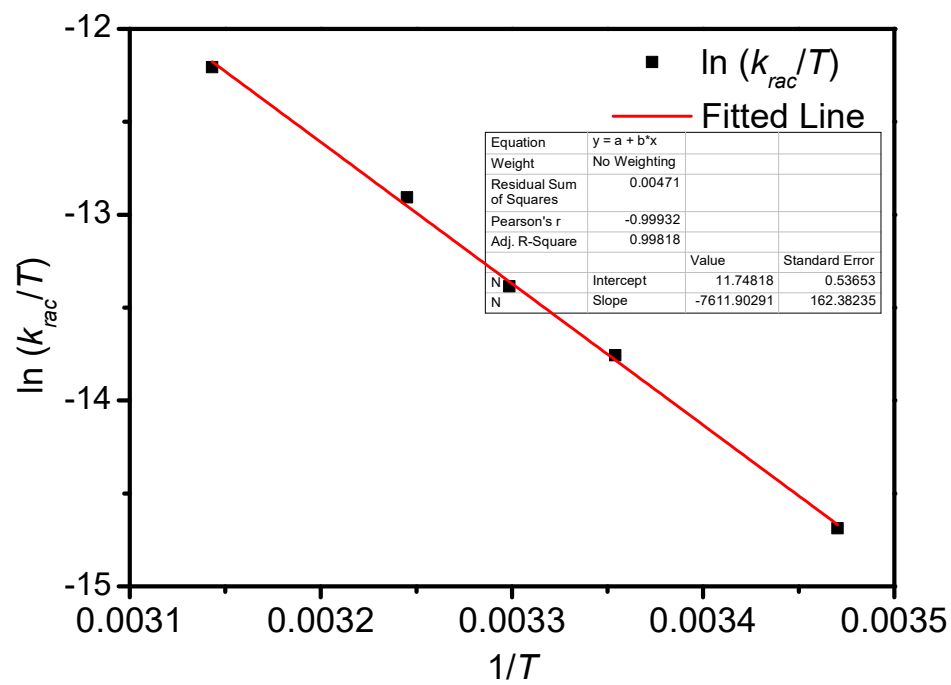

Figure A11. Eyring plots for the racemization of BP-f1 in $\mathrm{MeOH}$. 


\section{References}

1. Takenaka, S.; Matsuura, N.; Tokura, N. Induced circular dichroism of benzoylbenzoic acids in $\beta$-cyclodextrin. Tetrahedron Lett. 1974, 15, 2325-2328. [CrossRef]

2. Kodaka, M. Application of a General Rule to Induced Circular Dichroism of Naphthalene Derivatives Complexed with Cyclodextrins. J. Phys. Chem. A 1998, 102, 8101-8103. [CrossRef]

3. Kodaka, M. A general rule for circular dichroism induced by a chiral macrocycle. J. Am. Chem. Soc. 1993, 115, 3702-3705. [CrossRef]

4. $\mathrm{Pu}, \mathrm{L}$. Fluorescence of Organic Molecules in Chiral Recognition. Chem. Rev. 2004, 104, 1687-1716. [CrossRef] [PubMed]

5. Zhang, X.X.; Bradshaw, J.S.; Izatt, R.M. Enantiomeric Recognition of Amine Compounds by Chiral Macrocyclic Receptors. Chem. Rev. 1997, 97, 3313-3362. [CrossRef] [PubMed]

6. Khose, V.N.; John, M.E.; Pandey, A.D.; Borovkov, V.; Karnik, A.V. Chiral Heterocycle-Based Receptors for Enantioselective Recognition. Symmetry 2018, 10, 34. [CrossRef]

7. Collman, J.P.; Wang, Z.; Straumanis, A.; Quelquejeu, M.; Rose, E. An Efficient Catalyst for Asymmetric Epoxidation of Terminal Olefins. J. Am. Chem. Soc. 1999, 121, 460-461. [CrossRef]

8. Gao, J.; Martell, A.E. Novel chiral N4S2- and N6S3-donor macrocyclic ligands: Synthesis, protonation constants, metal-ion binding and asymmetric catalysis in the Henry reaction. Org. Biomol. Chem. 2003, 1, 2801-2806. [CrossRef]

9. Du, G.; Andrioletti, B.; Rose, E.; Woo, L.K. Asymmetric Cyclopropanation of Styrene Catalyzed by Chiral Macrocyclic Iron(II) Complexes. Organometallics 2002, 21, 4490-4495. [CrossRef]

10. Yang, C.; Mori, T.; Inoue, Y. Supramolecular Enantiodifferentiating Photocyclodimerization of 2-Anthracenecarboxylate Mediated by Capped $\gamma$-Cyclodextrins: Critical Control of Enantioselectivity by Cap Rigidity. J. Org. Chem. 2008, 73, 5786-5794. [CrossRef]

11. Yao, J.; Yan, Z.; Ji, J.; Wu, W.; Yang, C.; Nishijima, M.; Fukuhara, G.; Mori, T.; Inoue, Y. Ammonia-Driven Chirality Inversion and Enhancement in Enantiodifferentiating Photocyclodimerization of 2-Anthracenecarboxylate Mediated by Diguanidino- $\gamma$-cyclodextrin. J. Am. Chem. Soc. 2014, 136, 6916-6919. [CrossRef] [PubMed]

12. Wei, X.; Wu, W.; Matsushita, R.; Yan, Z.; Zhou, D.; Chruma, J.J.; Nishijima, M.; Fukuhara, G.; Mori, T.; Inoue, Y.; et al. Supramolecular Photochirogenesis Driven by Higher-Order Complexation: Enantiodifferentiating Photocyclodimerization of 2-Anthracenecarboxylate to Slipped Cyclodimers via a 2:2 Complex with ß-Cyclodextrin. J. Am. Chem. Soc. 2018, 140, 3959-3974. [CrossRef] [PubMed]

13. Lv, Y.; Xiao, C.; Yang, C. A pillar[5]arene-calix[4]pyrrole enantioselective receptor for mandelate anion recognition. New J. Chem. 2018, 42, 19357-19359. [CrossRef]

14. Fan, C.; Wu, W.; Chruma, J.J.; Zhao, J.; Yang, C. Enhanced Triplet-Triplet Energy Transfer and Upconversion Fluorescence through Host-Guest Complexation. J. Am. Chem. Soc. 2016, 138, 15405-15412. [CrossRef] [PubMed]

15. Ogoshi, T.; Kanai, S.; Fujinami, S.; Yamagishi, T.-A.; Nakamoto, Y. para-Bridged Symmetrical Pillar[5]arenes: Their Lewis Acid Catalyzed Synthesis and Host-Guest Property. J. Am. Chem. Soc. 2008, 130, 5022-5023. [CrossRef] [PubMed]

16. Gui, J.-C.; Yan, Z.-Q.; Peng, Y.; Yi, J.-G.; Zhou, D.-Y.; Zhong, Z.-H.; Gao, G.-W.; Su, D.; Wu, W.-H.; Yang, C. Enhanced head-to-head photodimers in the photocyclodimerization of anthracenecarboxylic acid with a cationic pillar[6]arene. Chin. Chem. Lett. 2016, 27, 1017-1021. [CrossRef]

17. Yang, Y.-F.; Hu, W.-B.; Shi, L.; Li, S.-G.; Zhao, X.-L.; Liu, Y.A.; Li, J.-S.; Jiang, B.; Ke, W. Guest-regulated chirality switching of planar chiral pseudo[1]catenanes. Org. Biomol. Chem. 2018, 16, 2028-2032. [CrossRef]

18. Ogoshi, T.; Akutsu, T.; Yamafuji, D.; Aoki, T.; Yamagishi, T.-A. Solvent- and Achiral-Guest-Triggered Chiral Inversion in a Planar Chiral pseudo[1]Catenane. Angew. Chem. 2013, 125, 8269-8273. [CrossRef]

19. Li, S.-H.; Zhang, H.-Y.; Xu, X.; Liu, Y. Mechanically selflocked chiral gemini-catenanes. Nat. Commun. 2015, 6, 7590. [CrossRef]

20. Yao, J.; Wu, W.; Liang, W.; Feng, Y.; Zhou, D.; Chruma, J.J.; Fukuhara, G.; Mori, T.; Inoue, Y.; Yang, C. Temperature-Driven Planar Chirality Switching of a Pillar[5]arene-Based Molecular Universal Joint. Angew. Chem. Int. Ed. 2017, 56, 6869-6873. [CrossRef] 
21. Strutt, N.L.; Fairen-Jimenez, D.; Iehl, J.; Lalonde, M.B.; Snurr, R.Q.; Farha, O.K.; Hupp, J.T.; Stoddart, J.F. Incorporation of an A1/A2-Difunctionalized Pillar[5]arene into a Metal-Organic Framework. J. Am. Chem. Soc. 2012, 134, 17436-17439. [CrossRef] [PubMed]

22. Ogoshi, T.; Yamafuji, D.; Akutsu, T.; Naito, M.; Yamagishi, T.-A. Achiral guest-induced chiroptical changes of a planar-chiral pillar[5]arene containing one $\pi$-conjugated unit. Chem. Commun. 2013, 49, 8782-8784. [CrossRef] [PubMed]

23. Guan, Y.; Liu, P.; Deng, C.; Ni, M.; Xiong, S.; Lin, C.; Hu, X.-Y.; Ma, J.; Wang, L. Dynamic self-inclusion behavior of pillar[5]arene-based pseudo[1]rotaxanes. Org. Biomol. Chem. 2014, 12, 1079-1089. [CrossRef] [PubMed]

24. Hu, W.-B.; Hu, W.-J.; Zhao, X.-L.; Liu, Y.A.; Li, J.-S.; Jiang, B.; Wen, K. A1/A2-Diamino-Substituted Pillar[5]arene-Based Acid-Base-Responsive Host-Guest System. J. Org. Chem. 2016, 81, 3877-3881. [CrossRef] [PubMed]

25. Ishi-i, T.; Crego-Calama, M.; Timmerman, P.; Reinhoudt, D.N.; Shinkai, S. Enantioselective Formation of a Dynamic Hydrogen-Bonded Assembly Based on the Chiral Memory Concept. J. Am. Chem. Soc. 2002, 124, 14631-14641. [CrossRef] [PubMed]

26. Dai, L.; Wu, W.; Liang, W.; Chen, W.; Yu, X.; Ji, J.; Xiao, C.; Yang, C. Enhanced chiral recognition by $\gamma$-cyclodextrin-cucurbit [6] uril-cowheeled [4] pseudorotaxanes. Chem. Commun. 2018, 54, 2643-2646. [CrossRef]

27. Huang, Q.; Jiang, L.; Liang, W.; Gui, J.; Xu, D.; Wu, W.; Nakai, Y.; Nishijima, M.; Fukuhara, G.; Mori, T. Inherently chiral azonia [6] helicene-modified $\beta$-cyclodextrin: Synthesis, characterization, and chirality sensing of underivatized amino acids in water. J. Org. Chem. 2016, 81, 3430-3434. [CrossRef]

28. Rao, M.; Kanagaraj, K.; Fan, C.; Ji, J.; Xiao, C.; Wei, X.; Wu, W.; Yang, C. Photocatalytic Supramolecular Enantiodifferentiating Dimerization of 2-Anthracenecarboxylic Acid through Triplet-Triplet Annihilation. Org. Lett. 2018, 20, 1680-1683. [CrossRef]

29. Wei, X.; Yu, X.; Zhang, Y.; Liang, W.; Ji, J.; Yao, J.; Rao, M.; Wu, W.; Yang, C. Enhanced irregular photodimers and switched enantioselectivity by solvent and temperature in the photocyclodimerization of 2-anthracenecarboxylate with modified $\beta$-cyclodextrins. J. Photochem. Photobiol. A Chem. 2019, 371, 374-381. [CrossRef]

30. Yan, Z.; Huang, Q.; Liang, W.; Yu, X.; Zhou, D.; Wu, W.; Chruma, J.J.; Yang, C. Enantiodifferentiation in the photoisomerization of (z, z)-1, 3-cyclooctadiene in the cavity of $\gamma$-cyclodextrin-curcubit [6] uril-wheeled [4] rotaxanes with an encapsulated photosensitizer. Org. Lett. 2017, 19, 898-901. [CrossRef]

31. Yang, C.; Nishijima, M.; Nakamura, A.; Mori, T.; Wada, T.; Inoue, Y. A remarkable stereoselectivity switching upon solid-state versus solution-phase enantiodifferentiating photocyclodimerization of 2-anthracenecarboxylic acid mediated by native and 3, 6-anhydro- $\gamma$-cyclodextrins. Tetrahedron Lett. 2007, 48, 4357-4360. [CrossRef]

32. Chen, Q.; Bao, Y.; Yang, X.; Dai, Z.; Yang, F.; Zhou, Q. Umpolung of o-Hydroxyaryl Azomethine Ylides: Entry to Functionalized $\gamma$-Aminobutyric Acid under Phosphine Catalysis. Org. Lett. 2018, 20, 5380-5383. [CrossRef] [PubMed]

33. Yu, X.; Liang, W.; Huang, Q.; Wu, W.; Chruma, J.J.; Yang, C. Room-temperature phosphorescent $\gamma$-cyclodextrin-cucurbit [6] uril-cowheeled [4] rotaxanes for specific sensing of tryptophan. Chem. Commun. 2019, 55, 3156-3159. [CrossRef]

34. Li, J.-T.; Wang, L.-X.; Wang, D.-X.; Zhao, L.; Wang, M.-X. Synthesis, Resolution, Structure, and Racemization of Inherently Chiral 1,3-Alternate Azacalix[4]pyrimidines: Quantification of Conformation Mobility. J. Org. Chem. 2014, 79, 2178-2188. [CrossRef]

35. Imamura, T.; Maehara, T.; Sekiya, R.; Haino, T. Frozen Dissymmetric Cavities in Resorcinarene-Based Coordination Capsules. Chem. Eur. J. 2016, 22, 3250-3254. [CrossRef] [PubMed]

36. Tan, L.-L.; Zhang, Y.; Li, B.; Wang, K.; Zhang, S.X.-A.; Tao, Y.; Yang, Y.-W. Selective recognition of "solvent" molecules in solution and the solid state by 1,4-dimethoxypillar[5]arene driven by attractive forces. New J. Chem. 2014, 38, 845-851. [CrossRef]

37. Boinski, T.; Szumna, A. A facile, moisture-insensitive method for synthesis of pillar[5]arenes-The solvent templation by halogen bonds. Tetrahedron 2012, 68, 9419-9422. [CrossRef]

38. Hu, X.-S.; Deng, H.-M.; Li, J.; Jia, X.-S.; Li, C.-J. Selective binding of unsaturated aliphatic hydrocarbons by a pillar[5]arene. Chin. Chem. Lett. 2013, 24, 707-709. [CrossRef] 
39. Ogoshi, T.; Masaki, K.; Shiga, R.; Kitajima, K.; Yamagishi, T.-A. Planar-Chiral Macrocyclic Host Pillar[5]arene: No Rotation of Units and Isolation of Enantiomers by Introducing Bulky Substituents. Org. Lett. 2011, 13, 1264-1266. [CrossRef]

40. Reichardt, C.; Welton, T. Solvents and Solvent Effects in Organic Chemistry, 4th ed.; John Wiley \& Sons: Hoboken, NJ, USA, 2011; pp. 455-460. 